\title{
PROPOSTAS PEDAGÓGICAS PARA O ENSINO DE HISTÓRIA EM CIRCULAÇÃO NA REVISTA NOVA ESCOLA (1997 a 2006).
}

\section{EDUCATIONAL PROPOSALS FOR OUTSTANDING HISTORY TEACHING IN REVIEW NEW SCHOOL ( 1997-2006 )}

\author{
[Título resumido: Revista Nova História e Ensino de História]
}

\author{
Elisangela Alves do Reis Silva ${ }^{1}$ \\ Elaine Rodrigues ${ }^{2}$ \\ Ednéia Regina Rossi ${ }^{3}$
}

\section{Resumo:}

Este artigo investiga as propostas para o Ensino de História na imprensa pedagógica Revista Nova Escola. Um periódico de regularidade mensal, distribuído, por meio de convênio, a todas as escolas brasileiras desde 1986 até os dias atuais. Para tanto, operou-se materialmente 23 exemplares do impresso publicados entre 1997 à 2006, a partir da preocupação de evidenciar quais as propostas de ensino de história foram entendidas pela Revista Nova Escola como socialmente válidas e merecedoras de veiculação? E, quais aproximações o impresso estabelece com o Parâmetro Curricular Nacional de História (PCN)? Os resultados evidenciam que as propostas para o ensino de História veiculadas no impresso apresentam vestígios anacrônicos, pouco fundamentados, reafirmando alguns saberes históricos. Também há similaridades entre as propostas veiculadas pela Revista (currículo não formal) com o PCN de História (currículo formal). Nas atividades propostas se observa a manutenção da primazia do documento escrito e u ma presença tímida de trabalhos com o patrimônio histórico. Contudo, apresentam elementos adequados e pertinentes ao redimensionamento do Ensino de História por meio dessas fontes.

Palavras-chaves: Educação, História da Educação, Currículo não Formal, Práticas Pedagógicas.

\section{EDUCATIONAL PROPOSALS FOR OUTSTANDING HISTORY TEACHING IN REVIEW NEW SCHOOL ( 1997-2006 )}

\section{Abstract}

Under the assumptions of the historiographical operation that article intends to investigate the proposals for the History of Education in the pedagogical press magazine New School. A regular monthly journal, distributed through an agreement to all Brazilian schools since 1986. Therefore, it operated 23 copies of printed material published between 1997 to 2006 cataloged, analyzed and compared circled the operative issues: What proposals are understood by the New Revised School as socially valid and therefore deserve serving? Which approaches the printed sets with Parameter National Curriculum History? The results show that the proposals for the teaching of history conveyed in the printed feature anachronistic vestiges, some reasoned, reaffirming some historical knowledge; there are similarities between the proposals circulated by the magazine (not formal curriculum) with the PCN

\footnotetext{
${ }^{1}$ Mestre em Educação pela Universidade Estadual de Maringá

${ }^{2}$ Professora Associada do Programa de Pós-Graduação em Educação da Universidade Estadual de Maringá

${ }^{3}$ Professora Associada do Programa de Pós-Graduação em Educação da Universidade Estadual de Maringá
} 
(formal curriculum) History, however, the proposed activities is evident maintaining the primacy of the written document and there timid presence of works with historical heritage, in However, the proposals suggest that work in this direction have appropriate and relevant elements to resize the History teaching through these sources.

Keywords: Education, History of Education, Non-formal Curriculum, Teaching Practices.

\section{INTRODUÇÃO}

No cenário de discussões e entraves acalorados acerca dos acontecimentos políticos, sociais e ideológicos da Nova República, em março de 1986 a Revista Nova Escola emerge como um veículo de interpretação e reinterpretação dos principais discursos pedagógicos do Brasil. Há 29 anos ininterruptos de publicações mensais se caracteriza como fecunda fonte para a escrita da História da Educação tanto no que se refere aos ideais pedagógicos como ao número expressivo de tiragem.

Essa pesquisa parte do pressuposto de que a História não pode ser apreendida em sua totalidade, sendo necessária a realização de uma operação historiográfica que ao historiador de ofício e também ao historiador da educação compete realizar, ou seja, a eleição das fontes, a definição do recorte espacial e temporal, o traçar dos objetivos e a escolha dos procedimentos metodológicos. (CERTEAU, 1982).

Assim, elegeu-se como fonte o impresso pedagógico Revista Nova Escola, tal escolha teve em sua origem, a percepção da importância em mostrar como esse material pode ser considerado um documento representativo para a apreensão da diversidade do campo educativo e assim, para a escrita da História da Educação. (NÓVOA, 2002).

Em história, tudo começa com o gesto de separar, de reunir, de transformar em "documentos" certos objetos distribuídos de outra maneira. Esta nova distribuição cultural é o primeiro trabalho. Na realidade, ela consiste em produzir tais documentos, pelo simples fato de recopiar, transcrever ou fotografar estes objetos mudando ao mesmo tempo o seu lugar e o seu estatuto. Este gesto consiste em "isolar" um corpo,como se faz em física, e em "desfigurar" as coisas para constituí-las como peças que preencham lacunas de um conjunto, proposto a priori. (CERTEAU, 1982, p. 80).

Para tanto, foram selecionadas como fonte 23 exemplares do impresso, publicados de 1997 a 2006, que traziam no índice a seção denominada História, catalogadas, agrupadas e sistematizadas por temas recorrentes compilaram na narrativa dos ideias pedagógicos em circulação impresso. 
A Revista Nova Escola não é um currículo oficial, no entanto ao dar e/ou veicular sugestões metodológicas, esta pesquisa a caracteriza como um currículo não-formal, pois sugere a comunidade docente encaminhamentos diretamente ligados ao currículo oficial de forma inteligível, com uma linguagem simplificada e sintática.

Diante disso, o estudo indaga: Quais ideais pedagógicos acerca da disciplina de História estão em circulação na Revista Nova Escola? Quais aproximações o impresso estabelece com o Parâmetro Curricular Nacional de História?

A Revista Nova Escola se autoprojeta ao sujeito leitor como um agente colaborador de uma educação de qualidade, no que se refere à formação de professores e ao Ensino Fundamental público. Mesmo não sendo um currículo formal, apresenta conceitos, modelos e experiências apontadas como inovadoras, que intentam dar ao professor/leitor o sentimento de pertencimento a uma classe de professores bem "sucedida", caso acate as suas sugestões didáticas veiculadas.

Nesse sentido o presente estudo subentende que nas propostas dirigidas ao Ensino de História, a Revista Nova Escola faz interpretação e/ou representação do currículo oficial, ou seja, veicula sob sua perspectiva um conjunto de prescrições oriundas das diretrizes curriculares, produzidas em âmbito nacional, com base nos documentos oficiais, nas propostas pedagógicas e nos regimentos escolares. Vamos à eles!

\section{A REVISTA NOVA ESCOLA: MATERIALIDADE E SUJEITOS LEITORES}

“A imprensa pedagógica é, provavelmente, o local que facilita um bom conhecimento das realidades educativas, uma vez que nela se manifestam, de um ou de outro modo, o conjunto dos problemas dessa área" (NÓVOA, 2002, p. 31). Bastos (2002, p. 73) destaca que ela se "constitui como um dispositivo que serve para a reflexão sobre o modo de produção do discurso do ser docente, e como um mecanismo de formação contínua". OLIVEIRA (2012, p. 9) define como imprensa "aquela que pode revelar os diversos elementos que compõem o sistema de ensino".

Nessa perspectiva CHARTIER (2002) e CERTEAU (2006) subsidiam os procedimentos teórico-metodológicos que auxiliam a compreensão de que a imprensa pedagógica divulga discursos e expressões de diferentes agentes, desta forma possibilita diálogos que representam particularidades de determinados grupos. 
[...] podem ser entendidos como núcleo de informação, já que mostram maneiras de produzir e difundir discursos. Há que se ter cuidado para não cair na tentação de supor que ali se encontra a história verdadeira, "o que realmente aconteceu"; contudo, é inegável que as notícias, os artigos dirigidos aos professores e as polêmicas subsequentes ajudam a configurar um painel mais vivo e revelador das ações dos personagens diretamente envolvidos naquelas questões e das redes que lhes dão sustentação (FERNANDES, 2008, p. 16).

Destarte as ideias veiculadas em um impresso pedagógico representa a opinião de determinado grupo, não sendo, portanto, verdade absoluta, tampouco mentirosa, mas representativa dos interesses e verdades desse (CHARTIER, 1991), desta form a a Revista Nova Escola é um lugar de produção de sentido, pois visa um leitor sob determinadas intenções ou finalidades, embora busque transparecer neutralidade ao apresentar modos de ser, pensar e agir de docentes entendidos como melhores, é preciso “compreender quais determinados procedimentos de textualização e retórica e de composição técnica é empregado pelo editor com o propósito de conduzir o leitor à compreensão que julga conveniente”. (CHARTIER, 1996, p. 96, 254).

Mas, afinal o que consiste a materialidade do impresso? Chartier (2007, p. 30) destaca que [...] geralmente é um objeto, um manuscrito ou um impresso, mas também pode ser uma forma de representação do texto sobre o palco"[...], ou seja, a materialidade é a forma como se organiza um texto para orientar a sua leitura, apreensão e compreensão. Identificar a materialidade de um impresso permite ao pesquisador pontuar as representações inscritas nos textos e o grupo que a produziu.

[...]Daí a necessária separação de dois tipos de dispositivos: os que decorrem do estabelecimento do texto, das estratégias de escrita, das intenções do "autor"; e os dispositivos que resultam da passagem a livro ou a impresso, produzidos pela decisão editorial ou pelo trabalho da oficina, tendo em vista leitores ou leituras que podem não estar de modo nenhum em conformidade com os pretendidos pelo autor. (CHARTIER, 1990, p. 126).

No entanto, não podemos separar a "[...] materialidade do texto da materialidade do objeto que lhe dá suporte", no caso a revista (CHARTIER, 2007, p.13), destaca-se a seção História da Revista Nova Escola em capa, miolo, gramatura do papel, organicidade da seção História e outros elementos que compõe sua materialidade, pois, cada fonte 
tem suas especificidades materiais, oriundas do seu local e objeto de produção, conheçamos portanto, a materialidade do impresso pedagógico Revista Nova Escola.

De acordo com Ramos (2009, p. 47) o impresso pedagógico surge para ser um segmento de mercado que apresente ao professor as mudanças educacionais em vigor, prova disso, é o nome (Nova Escola) do impresso pedagógico que representa enfaticamente a intenção de transmitir um sentido de inovação no campo da educação, por meio de informações recentes sobre a escola brasileira.

O apoio dos órgãos oficiais é evidenciado em todas as capas, que traz o símbolo do MEC, FNDE, BIBLIOTECA DA ESCOLA, ou ainda os três juntos. Este estudo entende que o impresso pedagógico é aceito pelos pares (esta pesquisa entende como pares todos os agentes que direta ou indiretamente, recebem, distribuem ou orientam a utilização da Revista Nova Escola), pois, compõe o portal de periódicos da Coordenação de Aperfeiçoamento de Pessoal de Nível Superior (CAPES), além do investimento de mais de 8 milhões de reais do Governo Federal. As informações aqui apresentadas, sugestionam que a Revista Nova Escola é autorizada pelos pares, na medida em que o próprio FNDE $^{9}$ comunga da opinião de que o periódico deixa o professor informado sobre a situação educacional do país e assim contribui para a formação do mesmo. Pode- se afirmar, que a Revista Nova Escola é um recurso de formação, assim entendidas pelo Ministério da Educação. (RAMOS, 2009).

Ao analisar os aspectos materiais que dão suporte ao texto veiculado na Revista Nova Escola, foi possível perceber que não há uma padronização do layout da capa, a regularidade acontece somente no que se refere à localização da palavra ESCOLA. A capa da Nova Escola é produzida em papel couchê brilhoso, de gramatura 115, as demais páginas, caracterizadas como miolo, são de papel SC $\mathrm{A}^{4}, 52 \mathrm{~g}$, assim o formato final da revista é de 20,2 x 26,6 cm., com lombada canoa ${ }^{5}$.

Não há publicação no mês de Janeiro, o número de páginas da seção História publicadas anualmente variam entre 1 e 14, perfazendo um total de 83 laudas no recorte de 1997 a 2006. A Revista Nova Escola compõem-se em média de 58 páginas internas e 4 páginas de capa, totaliza assim 62 páginas; no entanto, a quantidade de páginas não é regular, no período pesquisado algumas revistas apresentam uma variação de 8 páginas para

\footnotetext{
4 Tipo de papel não-revestido, supercalandrado, fabricado com pasta de alto rendimento, utilizado na rotogravura para impressão de encartes de jornal, catálogos, revistas, e outros.

5 Lombada canoa é o acabamento dos cadernos unidos por grampos, esse tipo de acabamento é indicado para revistas em revistas que tenham em torno de 60 páginas.
} 
mais ou para menos.

Ainda no que tange a materialidade do impresso, foi possível verificar que houve mudança nos dísticos enunciativos da Revista Nova Escola ao longo dos anos, sob esse pressuposto, Silveira (2006) auxilia faz alguns apontamentos, que foram sistematizados pela autora.

Da primeira publicação no ano de 1986 a 1994, a autora destaca que as matérias que foram mais evidenciadas tratavam de temáticas mais voltada a prática, sendo elas: deficiências da educação, dificuldades dos professores, apontamentos do que era e o que idealizava para a educação, e outras. Com a morte de Victor Civita em 1991, Roberto Civita passa a ser o diretor da Fundação Civita. Em 1991, percebe-se a primeira mudança na estrutura da revista, com singela modificação do layout e a inserção de novas seções.

De 1995 a 1997 as temáticas que envolviam as TIC's eram assuntos abordados em todos os segmentos. Assim, a NOVA ESCOLA sofre transformações para se adequar à essas tecnologias e, principalmente no que refere-se ao uso das mesmas aliadas as transformações pedagógicas oriundas das Reformas Educacionais. Ao considerar as reformas, Silveira (2006) afirma que em março de 1995, o então ministro da Educação Paulo Renato de Souza, concede uma entrevista a revista, onde, apresenta as 4 etapas de um plano de ação que visava a melhoria da educação em nível fundamental, daquele período, principalmente com a Lei 9394/96. Até o momento ela se caracteriza como “A revista do ensino de $1^{\circ}$ grau.

Durante os anos de 1998 e 1999 a revista se institui como "A revista do ensino fundamental". A referida faz novamente uma entrevista com o então ministro, que faz um resumo dos avanços que fortaleceu o ensino fundamental nos anos anteriores. Enfatizando a importância dos PCN's, da TV Escola, Avaliação do livro didático e etc. As abordagens da revista nesse período enfatizam o sistema nacional de avaliação da educação básica (Saeb) e as novas tecnologias, assuntos ligados às reformas.

A partir do ano de 2000 a revista muda o seu slogan, com um foco mais concentrados nos planejamentos (considerando as disciplinas escolares do Ensino Fundamental). Passando a anunciar "A Revista do Professor". O enfoque desse período traz além das reportagens e seções, uma seção com orientações específicas para os docentes, denominada "Caderno de Atividades".

Já em 2006 a revista passa a se posicionar como “A REVISTA DE QUEM EDUCA”, a partir desse período a palavra ESCOLA, antes evidenciada em letra maiúscula nas capas, recebe o formato minúsculo.

Ao identificar alguns elementos materiais da Revista Nova Escola este estudo 
compreende que o impresso pedagógico analisado apresenta um modelo de currículo não formal que contém interpretações ou representações sobre os currículos escritos. Mesmo não sendo a expressão direta destes, "traduz", explica um significado e, nesse processo, produz outros significados, ou seja, ao trasladar um sentido "manipula-se" o texto de outro e se elabora outra versão, não é desinteressada e nem imparcial.

\begin{abstract}
A Revista Nova Escola é um espaço em que os enunciados oficiais curriculares são reorganizados ao serem reduplicados, fabricando um modelo próprio de narrar o currículo, o que implica em determinadas representações sobre história e ensino de história e determinada materialidade como revista pertencente à cultura das mídias. Também é um espaço em que se delineiam dois níveis curriculares: o escolar, dos saberes (históricos) que deveriam ser ensinados na escola, e o formativo, dos saberes (pedagógicos) necessários para que os professores possam "ensinar bem" (a história). (RAMOS, 2009, p.33).
\end{abstract}

Chartier (2002) destaca questões voltadas à representação, ao considerar aspectos ligados à escrita pontua a força que um texto impresso possui em gerar sentidos depois do sistema de representação que a ele é apresentado, oriundo de sua cultura, assim a representação do mundo social é determinada pela relação de interesse do grupo que a produz, desta forma, cabe ressaltar que a empresa responsável pela produção da Revista Nova Escola, está inserida em um sistema capitalista que ao sabor da política educacional busca um espaço para a ampliação de seu capital. No bojo dessa ação a produção social da revista expressa um sistema de representação sobre o conceito de educação, professor, escola e nesse caso da disciplina de História aos seus leitores. Mas quem são esses sujeitos leitores?

Uma pesquisa realizada pela Projeção Brasil de Leitores Consolidado 2011 e publicada em Agosto de 2012, revela que a tiragem da Revista Nova Escola chega a de 682.614 exemplares por mês, sendo 322.281 de assinaturas, 36.136 vendidas avulsamente e 324.197 adquiridas pelo convênio com o FNDE, podendo alcançar a um total de 1.552.240 leitores diretos.

O maior público de leitores é caracterizado por mulheres, totalizando $75 \%$ e somente $25 \%$ do público masculino. Esse público, define-se por ainda ser predominante no contexto educacional, a presença feminina, sobretudo na Educação Infantil e Ensino Fundamental I.

Um maior percentual, (30\%) tem entre 35 a 44 anos, há $26 \%$ leitores de 25 34 anos. Esses dois maiores públicos mostra-nos a idade profissional dos leitores, em que 
na primeira se caracterizam em professores efetivos e que atuam a algum tempo na educação. O segundo dado, revela a idade dos leitores que fazem um curso de licenciatura e/ou professores que estão ingressando na carreira do magistério. Há um público de $15 \%$ dos leitores com idade acima de 50 anos, $10 \%$ de $45-49$, $8 \%$

de 10-14 anos, $7 \%$ entre 20-24 anos e 5\% de 15-19 anos.

A classe social predominante de leitores da Revista Nova Escola, refere-se à classe B com $61 \%$ dos leitores, seguidos da classe C com 30\%. Somente $8 \%$ do público leitor pertencem à classe $\mathrm{A}$ e $2 \%$ a classe $\mathrm{D}$. Não há leitores caracterizados na classe E. A predominância leitores que compõe a Classe denominada $\mathrm{B}$, se caracteriza, por termos os professores inseridos nesse contexto e que se enquadram na remuneração em torno de cinco salários mínimos.

Não é possível afirmar de forma assertiva porque a Revista Nova Escola trabalha com essa base de produção e distribuição, no entanto, pode-se entender que esses dados retratam o público-alvo de professores de Educação Infantil, Ensino Fundamental e estudantes de licenciatura, que ela denota no site. Ao traçarmos o perfil dos leitores do referido impresso, é importante identificar de onde falam os autores das reportagens que tratam o Ensino de História, para tanto, apresentamos na próxima subseção o lugar social de produção da revista.

\section{SEÇÃO HISTÓRIA: O QUE TENS A REVELAR?}

Em uma atividade arqueológica realizada em 106 exemplares do impresso de 1997 a 2006, o texto se pauta na análise de 23 que trazem a seção História no índice, caderno de atividades ou em edição especial.

Para fazer falar o dado é necessário a pesquisa, numa ação de desfossilização os procedimentos auxiliam o historiador a redistribuir os momentos da pesquisa (documentação, tratamento de separação, interpretação, e outros). (CERTEAU, 2002). Sob essa perspectiva os impressos pedagógicos foram classificados por reportagens com assuntos próximos; no processo de orientação chegamos à sistematização por eixos temáticos. Assim, as ideias pedagógicas encontram-se organizadas segundo os eixos temáticos: passado e tempo. Cabe esclarecer que o agrupamento por eixos temáticos, foi uma estratégia operacional instituída pela autora, partindo dos critérios de frequência, abordagem e tema gerador associado aos referidos eixos em que:

O eixo denominado Passado veicula experiências metodológicas que mostram ao docente como abordar o presente e futuro nas aulas de História, enfatiza aponta 
experiências relacionadas ao cotidiano, lembranças e desvendamento do passado.

O eixo denominado Tempo constituísse em questões ligadas ao cenário político nacional e internacional, com experiências acerca da carreira política de Getúlio Vargas, movimento feminista, futebol e moda.

Essa sistematização foi necessária para que com base na compreensão pontuada por Goodson (1995 p. 8) de que “o currículo não é constituído de conhecimentos válidos, mas de conhecimentos considerados socialmente válidos", questionássemos: Quais conhecimentos/conteúdos relacionados ao Ensino de História são compreendidos pela Revista Nova Escola como socialmente válidos e merecem veiculação?

Encontramos o eixo denominado Passado: cotidiano e lembranças nas seções de 1999, 2002 e 2006. Em 1999, por meio da reportagem "A história local do Rio de Janeiro". A seção que traz, conforme o quadro, o índice diferente da reportagem, mostra como os jogos podem ser utilizados na disciplina de História, quando o professor trabalhar com história local. A atividade é proposta a alunos de $3^{\mathrm{a}}$ a $6^{\mathrm{a}}$ série do Colégio Estadual D. Pedro II, situado no Rio de Janeiro.

A seção é assinada por Carlos Fioravanti e Roberta Bencini detalha a sequência didática sistematizadas pelas docentes Ana Paula de Carvalho e Sonia Elza Chiara nas aulas. A reportagem destaca que durante vinte minutos um grupo de alunos da $3^{\mathrm{a}}$ série poderia atravessar as ruas modernas e antigas do Rio de Janeiro, numa viagem pelo tempo e espaço, localizando os pontos históricos, sem a necessidade que a turma saia da sala. A reportagem enaltece a atividade das professoras criadoras do jogo que engloba as disciplinas de história e geografia.

Com os Parâmetros Curriculares Nacionais a História Local, valorizada também como estudo do meio, o qual poderia contribuir para a formação do sentimento de pertencimento do aluno a um determinado grupo social e cultural, foi assumida como um dos eixos temáticos dos conteúdos de todas as séries iniciais e como perspectiva metodológica para toda a escola básica.

Segundo Schmidt (2007), essas diretrizes curriculares dão um tratamento ambíguo, mas não contraditório, à História Local: tanto como conteúdo (séries iniciais), quanto como recurso didático (em todas as séries), de forma que seja utilizada como fim e como meio para abordagem do Ensino de História nas séries iniciais, consolidando-se como fundamentação importante para essa disciplina, haja vista a relevância do professor conhecer os fundamentos que norteiam o Ensino de História de forma que não oferecê-la como um produto pronto e acabado ao aluno. 
[...] a história é um conhecimento construído a partir das questões colocadas pelo presente; a dimensão temporal e o contexto no qual as questões são produzidas influem decididamente em sua solução; diversas são as abordagens ou visões sobre o problema em questão, pois diferentes são os sujeitos que com eles dialogam de diferentes espaços sociais; para a sua compreensão, construção/reconstrução é fundamental o confronto das posições, assim como a identificação de suas argumentações e contra argumentações. (CIAMPI, 2011, p. $65)$.

A seção continua a destacar o projeto viagem pelo Rio de Janeiro, desenvolvido para $3^{\mathrm{a}}$ a $6^{\mathrm{a}}$ série, aplica os conceitos básicos de duas disciplinas. Em História, o jogo explora o cotidiano do presente, do passado e as transformações da cidade ao longo do tempo. "Nossa intenção é ajudar os alunos a abrir os olhos para a história da cidade em que vivem, contrapondo a paisagem atual como a do final do século passado", diz Ana Paula. Ao percorrerem os trajetos do tabuleiro, os alunos descobriram que o Rio do século XIX se estendia apenas do Centro até o bairro de São Cristovão, na Zona Norte. Hoje ele chega até a Barra da Tijuca, na Zona Oeste, a 30 quilômetros da região central. (NOVA ESCOLA, nº122, 1999, p.37).

De acordo com Matos (2011) as transformações ligadas a pós- modernidade, como por exemplo, a aceleração dos processos sociais, econômicos e de comunicação conduziram a uma "globalização" cultural, revelou um redimensionamento do passado e da memória coletiva, talvez por se distanciar das tradições locais e ameaçar o desaparecimento de referentes culturais, fez com que o campo das instituições e instrumentos voltados à tarefa do cuidado e preservação da memória e do patrimônio crescesse. Pode-se averiguar o acompanhamento dessa tendência na Revista Nova Escola, ao veicular práticas pedagógicas que associam memória, história local e educação patrimonial. No entanto, cabe ressaltar que:

A história local não é necessariamente o espelho da história de um país e de uma sociedade, pois, caso fosse, negaria a mediação em que se constitui a particularidade e imediatos, os quais não se repetem nos processos mais amplos, mas com eles se relacionam e, nesse sentido, auxiliam na compreensão do local com o geral [...]. (CIAMPI, 2011, p. 69).

O trabalho com a História Local deve utilizar procedimentos metodológicos que evitem ao aluno considerar sua vida pessoal, local, como o espaço onde não ocorre história, como se seu espaço estivesse à margem da história, deve-se oportunizar ao 
aluno a interação de modo que ele perceba que sua própria na história da escola, do bairro e do Brasil. (BITTENCOURT, 2007).

A proposta composta por 5 etapas apresenta ao leitor o passo a passo da atividade, percebemos que os encaminhamentos dispostos tentam fomentar o trabalho com heranças culturais. De acordo com o impresso, essa prática auxilia o aluno no resguardo da memória da sua comunidade e assim, construa o sentimento de pertencimento.

Após a exposição do passo a passo a revista traz em 1 parágrafo do lado esquerdo da página a recomendação do que o professor pode fazer ao terminar a partida. Na sequência, sugere ao docente que leve o aluno a fazer o registro do que se trabalhou na forma escrita/desenho.

Depois do jogo, sugira algumas atividades para as crianças, como escrever textos relatando as etapas do jogo. $O$ grupo que percorreu o presente deve escrever sobre fatos do passado e vice-versa. A turma pode também imaginar e desenhar as vestimentas dos personagens e os meios de transporte que eram utilizados para se locomoverem pela cidade. (REVISTA NOVA ESCOLA, 1999, p.39).

Schmidt (2007) reconhece que a História Local pode contribuir na produção de uma consciência histórica individual/coletiva e, portanto, importante elemento na recuperação da historicidade do aluno, de seus valores, do seu entorno, de seu país, enfim, de seu processo de formação identitária. Para tanto, confere centralidade à questão de princípios metodológicos abertos pelo ensino da História Local, notadamente os relacionados com os documentos e fontes de pesquisa e com o rompimento da tradicional linearidade histórica. O currículo da História Local, para Bittencourt (2004), ganha, necessariamente, contornos temporais e espaciais, portanto, deve-se propor conteúdos que possibilitem identificar a dinâmica do lugar, as transformações do espaço e a articulação entre o local, regional, nacional.

Cabe ressaltar que a História Local se compõe de algumas condições específicas, dentre elas: não ter como objetivo que o resultado da aprendizagem seja a elaboração da História, mas iniciar o aluno no método histórico para que ele possa ser capaz de compreender como se constroem os conceitos e as leis sobre o passado, selecionar as fontes mais próximas dos alunos, pela possibilidade de serem mais motivadoras e significativas e que o estudo da História Local sirva para oferecer e enriquecer as explicações da História geral, de “outros lugares”. (SCHMIDT, 2007).

Em análise, percebermos que emerge na explanação dessa proposta a forma 
como os autores apontam o trabalho com a imaginação histórica, no entanto a abordagem acontece de maneira descontextualizada ao se perder o intento, ou seja, o estudo da história, como processo de reconhecimento das mudanças e permanências, ou das transformações que ocorreram nas sociedades humanas na relação com o tempo presente. E ainda que não há uma relação efetiva com a "identidade sócio-histórica do aluno, demarcando em alguns momentos apenas questões geográficas da história local limitando a inscrevê-lo em seu grupo de convívio do tempo presente". (BITTENCOURT, 2000, p. 150).

Para pontuar a necessidade do professor perceber que a leitura de mundo do tempo presente do aluno é um laboratório de estudo para a aprendizagem em História, Peter Lee (2001), destaca que é o docente de História deve auxiliar o aluno no entendimento e utilização de procedimentos relacionados a construção historiográfica, de modo que, leve o aluno a observar, analisar e identificar que todo o conhecimento estudado é constituído, permitindo assim, que ela entenda a provisoriedade do conhecimento historicidade.

Ao sugerir que o professor leve o aluno a se colocar "no lugar de", a revista trabalha com a imaginação, pois não contrapõe o que conhece os alunos conhecem com outras fontes; está proposição é relevante, no entanto, não basta. Nesta metodologia, a pesquisa verificou que há ausência de elementos que levem a estudos que extrapolem o jogo em si. Diante disso podemos compreender que os encaminhamentos metodológicos apresentados apontam o jogo como uma atividade para reforçar um trabalho já desenvolvido, sem contextualização.

Bittencourt (2005) propõe identificar o enfoque e a abordagem de uma História Local que crie vínculos com a memória familiar, do trabalho, das festas, etc. para não incorrer em uma continuação dos pressupostos norteadores da História Nacional, ou seja, reproduzir a História do poder local fazendo os alunos conhecerem a vida e obra de antigos prefeitos e demais autoridades. Mas deixa clara a necessidade de distinção entre História e Memória. Assim, as metodologias tradicionais para a disciplina de História devem ser superadas, pois, "a história ensinada é fruto de recortes dependentes das problemáticas do presente" (BITTENCOURT, 2005, p.127).

Na mencionada atividade, há a ideia pedagógica de encaminhar os alunos para análise do passado de forma anacrônica ao não se discutir ou trazer para o estudo elementos que permitam reconhecer a forma de viver, o cotidiano, os valores deste e daquele tempo. Desta forma raciocínios dicotômicos que transformam o presente e o passado em unidades autônomas possibilita a ignorância do passado e a elaboração de julgamentos 
não pertinentes para a realidade de outro tempo. (SCHMIDT; CAINELLI, 2010).

A Seção História que trata o eixo Passado: cotidiano e lembranças enfatiza experiências educativas práticas, traz sugestões de atividades elaboradas por escolas e/ou professores, explicando o passo a passo da proposta sugestionada. A história é singular, parcial, não verdadeira, é sempre representativa, portanto construímos simplificações do passado. (LE GOFF, 2003). O enunciado "No tabuleiro passado e presente se encontram", mostra que a referida atividade possibilita deslocamentos temporais ao se deparar o aluno com o presente e o passado, de forma estanque e sem a consideração da continuidade histórica, análise das transformações, o que gera análises anacrônicas. Mesmo o exercício com a imaginação histórica é prejudicado pela ausência de contextualização.

Em uma das ideias pedagógicas veiculadas a Revista Nova Escola traz em tela a experiência de um professor que organizou um projeto que objetivava facilitar a compreensão de assuntos políticos e econômicos. De início podemos verificar que a Revista Nova Escola não traz ao professor nenhum aporte teórico que discuta os conceitos de temporalidade e/ou cotidiano.

De maneira abrupta destaca a proposta explicitamente, com começo, meio e fim, em que o fim é sempre evidenciado com um enaltecimento a instituição que realizou a experiência. "A ausência de um passado conhecido e reconhecido, a míngua de um passado, pode também ser fonte de grandes problemas de mentalidade ou identidade coletivas" (LE GOFF, 2003, p. 204), assim, ao não apresentar nenhum referencial que explane o conceito histórico ligado a História e Memória, nega ao leitor a possibilidade compreender com profundidade o assunto ou mesmo de pesquisá-lo.

[...] Mais do que sugerir temas para trabalhar em sala, importa,[...] chamar a atenção pelo fato de que, para o ensino, é necessário colocar sempre em perspectiva a relação estabelecida entre método histórico e método do ensino, tendo-se os aspectos históricos e epistemológicos como norteadores da reflexão pedagógica. (TOLEDO, 2011, p.26).

Este estudo compreende que a narrativa textual de um impresso tem suas especificidades e/ou limitações, no que refere-se à linguagem e ao suporte e temas apresentados, no entanto, se critica, não haver nas reportagens, nenhum link de pesquisa ou referências bibliográficas ao professor que deseje aprofundar no assunto, haja vista, que os autores que as assinam não tem formação em Educação ou História.

Destarte, a possibilidade de situar minimamente a questão histórica e os autores, 
para que o professor amplie os estudos, deveria fazer parte da proposta, pois assim, possibilitaria o reconhecimento dos referenciais teóricos utilizados.

A proposta está direcionada a turma de $6^{\mathrm{a}}$ série, a Revista Nova Escola mostra passo a passo como o professor realizou a atividade, que teve veiculação nacional por meio da edição de junho/julho 2002.

A primeira estratégia desenvolvida pelo professor que a Revista Nova Escola veicula é a utilização de slides com reproduções de pinturas famosas nas quais segundo ele, estão eternizados costumes e visões de mundo, decompor a obra e analisar seus detalhes é uma diversão para a turma e uma forma muito interessante de encontrar pistas do passado. Cenários, indumentárias, acessórios, expressões nada passa despercebido. Percebe-se a inserção de novas fontes, ao continuarmos a observação da proposta que destaca: "Dá para notar que havia uma distância muito grande entre o faraó e os camponeses, porque as roupas que eles usavam eram diferentes".

A inserção de novos recursos na disciplina de História é oriunda das novas vertentes que permitiram a ampliação de fontes no campo da História da Educação. Mesmo com a utilização de documentos inovadores, como por exemplo, as fotografias, percebe-se que a atividade não acrescenta informação no que se refere à potencialidade desta presença para o Ensino de história.

A segunda estratégia que o professor propõe é transformar em recurso pedagógico as lembranças que trouxe das viagens de férias ao Egito, no entanto sabe-se que é raro o professor que tem acesso a isso. O professor apresenta aliados a própria memória, documentos como papiros, trajes, peças de artesanato e muitas fotografias.

A Revista Nova Escola veicula uma nota na seção baseada em Ferreira Gullar que destaca: "A História humana não se desenrola apenas nos campos de batalha e nos gabinetes presidenciais. Ela se desenrola também nos quintais, entre plantas e galinhas, nas ruas de subúrbios, nas casas de jogos, nos prostíbulos, nos colégios nas usinas, nos namoros de esquinas". (NOVA ESCOLA, 2002, p.27). Nesse sentido o PCN de História denota que:

O estudo de novos temas, considerando a pluralidade de sujeitos em seus confrontos, alterando concepções calcadas apenas nos "grandes eventos" ou nas formas estruturalistas baseadas nos modos de produção, por intermédio dos quais desaparecem de cena homens e mulheres de "carne e osso", tem redefinido igualmente o tratamento metodológico da pesquisa. A investigação histórica passou a considerar a importância da utilização de outras fontes documentais, além da escrita, aperfeiçoando métodos de interpretação que abrangem os vários registros produzidos. A 
comunicação entre os homens, além de escrita, é oral, gestual, sonora e pictórica (BRASIL, 1999, p. 21).

$\mathrm{Na}$ terceira estratégia utilizada pelo docente e apresentada na revista refere-se a utilização de livros didáticos e paradidáticos para encontrar referências da vida cotidiana. Observamos que o impresso enaltece os relatos de pessoas mais velhas, casas antigas da cidade, objetos de decoração, padrões de comportamento e fotografias, "materiais considerados irrelevantes até bem pouco tempo atrás são algumas sugestões presentes nos Parâmetros Curriculares Nacionais. Qualquer coisa funciona para detonar essa investigação, desde que o educador saiba levantar as questões sobre ela". (REVISTA NOVA ESCOLA, 2002, p. 28).

Compreendemos por meio das semelhanças nas assertivas destacadas na Revista Nova Escola, que, além inserção de novas fontes, o impresso pedagógico defende ampliação das fontes e novas abordagens para o ensino de História, ou seja, no que se refere às teses de passado e lembranças, há convergência de ideais que legitimam, os conteúdos e metodologias considerados como socialmente válidos pelo currículo oficial. (GOODSON, 2003).

A proposta de atividade se caracteriza como pertinente por sugestionar o uso de diferentes fontes para o reconhecimento histórico cultural de outro tempo, no entanto, não faz relação com o tempo presente. Trazer objetos de produção recente no Egito é uma estratégia significativa, dependendo da abordagem do professor que necessita evitar que estes objetos percam a dimensão da transformação histórica e remeta ao tempo presente de produção em seus objetivos comerciais (turismo) o que é diferente da produção, no entanto, essa perspectiva não foi enunciada na sugestão. (SCHMIDT; CAINELLI, 2010).

A última edição que trata o assunto denominado Passado: cotidiano e lembranças está disposta no exemplar de 2006, a seção tem similaridades com o exemplar de 2002, no entanto, apresenta mais que apontamentos implícitos de atividades, traz um plano de aula completo em termos formais, pontuando dos objetivos ao processo de avaliação.

A tradição oral é destaque como sugestão de um recurso significativo para se trabalhar a disciplina de História, de acordo com o enunciado, a proposta auxilia os "estudantes a resgatarem o modo de vida e os costumes do povo tupiniquim".

$\mathrm{Na}$ manchete enfatiza que "Algumas lembranças, contadas pelos mais velhos, era tudo o que os alunos tinham sobre suas origens, a revista apresenta a experiência como uma atividade que intentar resgatar o passado do povo tupiniquim, afirmando que assim contribui para as crianças serem escritores da própria história”. A reportagem 
assinada por Meire Cavalcante ${ }^{28}$ destaca como as lembranças e as questões que as envolvem constituem objetos relevantes para o estuda da História, um deles refere-se a metodologia da história oral.

A Revista Nova Escola apresenta os alunos da Escola Municipal Pluridocente Indígena Pau-Brasil, localizada na zona rural de Aracruz (ES), que recebiam, de vez em quando, a visita de alunos de escolas urbanas. Muitos dos visitantes ficavam espantados com o que viam. Ou melhor, com o que não viam. Na aldeia, as crianças e os adultos não andam com o rosto pintado e de cocar na cabeça o tempo todo, moram em casas de alvenaria e assistem à televisão. "Por não se encaixarem nos estereótipos, as crianças sofriam discriminação sem sequer saber por quê", afirma a professora Andrea Cristina Almeida. Por isso, ela elaborou seu projeto, que teve duração de um mês. Com ele, além de aprender a ler e escrever, os alunos descobriram muito sobre suas origens e os hábitos de seus antepassados e entenderam as mudanças ocorridas ao longo dos anos que resultam num modo de vida diferente. A professora afirma que ao entrevistar os mais velhos e investigar suas origens, os alunos estariam trazendo de volta a cultura de seu povo. Este estudo entende que não há possibilidade de resgate da história, nem a apropriação dela como causa e consequência ou ainda como perspectiva para mudar ou melhorar o futuro, mas sim como atribuição de sentido, como possibilidades de compreensão do que foi representativo daquele período histórico, pois mesmo a história querendo ser objetiva, não pode ser. "Quer fazer reviver e só pode reconstruir. Ela quer tomar as coisas contemporâneas, mas ao mesmo tempo tem de reconstituir a distância e a profundidade da lonjura histórica”. (LE GOFF, 2003, p.22).

Percebemos nos ideias pedagógicos que circundam essa proposta, a disciplina de História não assume um posicionamento particular que lhe é cabido, aparece na maioria das vezes como suporte para outros conteúdos como a leitura e escrita, por exemplo, ou associada a disciplinas "auxiliares", como se não tivesse importância por si só, ou seja, a história não aparece como princípio e sim como meio. Não há abordagem da temática de maneira teorizada e fundamentada, as propostas são claras, porém, não oferece ao professor/leitor elementos que contribuam para o entendimento do conceito de cultura, além de apresentar um conceito tradicional de história ao veicular que a entrevista oral poderá trazer de volta a cultura do povo tupiniquim aos alunos.

No PCN esse modelo de proposta também é sugerido, no que se refere ao eixo de 
História local e do cotidiano, pois os alunos devem ter ampliados a capacidade de observar o entorno para compreender as relações sociais e econômicas que existem no seu próprio tempo e que assim reconheçam a presença de outros tempos no seu dia a dia, essas informações:

[...] propiciam pesquisas com depoimentos e relatos de pessoas da escola, da família e de outros grupos de convívio, fotografias e gravuras, observações e análises de comportamentos sociais e de obras humanas: habitações, utensílios caseiros, ferramentas de trabalho, vestimentas, brincadeiras, músicas, jogos e outros;[...]a preocupação em identificar grupos indígenas que habitam ou habitavam a região próxima do convívio dos alunos. (BRASIL, 1997, p.52).

Entendemos que as atividades extraclasses como (passeios, visitas e entrevistas) que partem da vivência do aluno e delimitam em como a turma pode realizar as experiências, mostram que a Revista Nova Escola veicula saberes pedagógicos que normativizam o modelo de ensino de história proposto pelo PCN de História, no entanto, o que fica aparente é a ideia de que a disciplina de História foi utilizada apenas como esteio para se trabalhar a Língua Portuguesa.

Na edição especial de 1999 sobre o PCN, chama-nos a atenção o discurso veiculado na Revista Nova Escola, enfatizando ao leitor que:

NADA É OBRIGATÓRIO. Atenção! Os PCN são orientações gerais de trabalho e só funcionam quando as sugestões que apresentam são adaptadas pelo professor à realidade dos alunos. O que se espera é que as idéias trazidas por eles sirvam como inspiração para a prática em sala de aula. Acreditamos que os parâmetros vão ajudar a fazer o planejamento escolar, nas reuniões com os pais de alunos e na organização, com o conjunto dos professores, de atividades que possam ser tratadas pelo maior número possível de disciplinas (NOVA ESCOLA, 1999, p. 4).

Esta pesquisa compreende que mesmo não sendo Revista Nova Escola um currículo formal, propõe atividades com os "ingredientes e o modo de fazer"; ao disponibilizar orientações ela mostra o que ao seu ponto de vista, são os modelos "autorizados", ou seja, ao apresentar experiências consideradas "eficazes" ao professorado e que estão concomitantes com o PCN, o impresso se torna uma representação direta do mesmo, interpretando-o com atividades práticas. 


\section{CONSIDERAÇÕE FINAIS}

Ao longo da narrativa buscou-se responder ao questionamento operante "Quais conteúdos são considerados socialmente válidos e merecem veiculação na Revista Nova Escola, bem como quais aproximações a Revista estabelece com o currículo oficial PCN'? Sem a pretensão de ser conclusivo, mas com o intuito de apontar caminhos, fez-se apontamentos a fim de compreender como a Revista Nova Escola se caracteriza como um currículo não formal, que veicula, interpreta e traduz saberes pedagógicos que normativizam o Ensino de História sugerido pelo currículo oficial, PCN.

Aferimos que algumas propostas veiculadas na Seção História se caracterizam como uma estratégia de divulgação, expansão e implantação dos saberes históricos defendidos pelo currículo oficial, em outras reafirma os saberes históricos já implantados. Cabe ressaltar que o saber pedagógico/histórico veiculado nas seções analisadas, não possuem referências, conceitualizações e argumentos, resume-se apenas a veiculação de experiências como modelos sugeridos.

Verificamos que a proposta, veiculada pelo periódico, de se ensinar partindo do presente, da realidade, do cotidiano do aluno, realizando "estudo do meio", em geral, retomam a história de vida, da família, da escola, do bairro e do município. Fotos do aluno e da família, realização de entrevistas com os pais, visitas a empresas e locais turísticos, são consideradas experiências que dariam a evidencia a "realidade do aluno", isso mostra-nos que a Revista Nova Escola as propostas em circulação apresentam elementos culturais e documentos inovadores como abordagem para o Ensino de História, com exceção da reportagem sobre o presidente Getúlio Vargas, em que o autor da seção propõe a construção de linhas do tempo, por meio de uma visão maniqueísta que tomam como base a cronologia; mostrando-nos que em algumas propostas ainda há resquícios do currículo do regime militar, que priorizava pelo ensino de amor à pátria pautado em heróis e datas.

A Revista Nova Escola, comunga da ideia de que um ensino de História tradicional se pauta unicamente em livros didáticos, valorização da memorização de nomes e eventos importantes, há a veiculação de ideias pedagógicas que enfatizam a história não linear, no entanto, o anacronismo rodeia algumas delas.

\section{REFERÊNCIAS}

BITTENCOURT, C. M. F. Capitalismo e cidadania nas atuais propostas curriculares de História. In: BITTENCOURT, C. M. F. (Org.). O saber histórico na sala de aula. 11. ed. São Paulo: Contexto, 1998. p. 11-27. 
BITTENCOURT, C. M. F. Ensino de História: fundamentos e métodos. 3. ed. São Paulo: Cortez, 2009.

BITTENCOURT, Circe Maria Fernandes. Disciplinas escolares; história e pesquisa. In TABORDA DE OLIVEIRA, Marcus. Aurélio; RANZI, Serlei Maria Fischer, (Org.) História das disciplinas escolares no Brasil: contribuições para o debate. Bragança Paulista: EDUSF, 2003.

BITTENCOURT, Circe Maria Fernandes. Ensino de história: fundamentos e métodos. São Paulo: Cortez, 2004. (Coleção Docência em Formação. Série Ensino Fundamental).

BITTENCOURT, Circe Maria Fernandes. Propostas curriculares de História: continuidades e transformações. In: BARRETO, Elba S. de Sa (org.). Os currículos do ensino fundamental para as escolas brasileiras. Coleção Formação de Professores. Campinas: Autores Associados; São Paulo: Fundação Carlos Chagas, 1998.

BITTENCOURT, Circe. Identidades e o ensino de História no Brasil. In: CARRETERO, Mario, ROSA, Alberto \& GONZÁLEZ, Maria Fernanda (orgs.) Ensino da História e Memória Coletiva. Porto Alegre: Artmed, 2007.

BRASIL. Parâmetros Curriculares Nacionais - Primeiro e Segundo Ciclos do ensino fundamental - História e Geografia. Brasil: MEC/SEF, 1997.

BRASIL. Parâmetros Curriculares Nacionais- Terceiro e Quarto ciclos do Ensino Fundamental- História e Geografia. Brasília: MEC/SEF, 1998.

CERTEAU, Michel de. A escrita da história. Tradução de Maria de Lourdes Menezes; revisão técnica de Arno Vogel.- 2 ed.- Rio de Janeiro:forense Universitária, 2010.

CERTEAU, Michel de. A invenção do cotidiano: artes do fazer. Tradução de Ephraim Ferreira Alves. Petrópolis: Vozes, 1994.

CHARTIER, Roger. A beira da falésia: a história entre incertezas e inquietude. Tradução de Patrícia Chittoni Ramos. Porto Alegre: Ed. Universidade/UFRGS, 2002.

FERNANDES, Ana Lúcia Cunha. O impresso e a circulação de saberes pedagógicos: apontamentos sobre a imprensa pedagógica na história da educação. In: MAGALDI, Ana Maria Bandeira de Mello; XAVIER, L. N. (Org.). Impressos e história da educação: usos e destinos. Rio de Janeiros: 7 Letras, 2008. p. 15-29.

GOODSON, Ivor F. Currículo: teoria e história; tradução de BRUNETTA, Attílio; revisão da tradução de FRANCISHETTI, Hamilton; apresentação de SILVA, Tomaz Tadeu da. Rio de Janeiro: Vozes, 1995.

GOODSON, Ivor. A construção social do currículo. Lisboa: Educa, 1997.

LE GOFF, Jacques. História e Memória. Tradução de Bernardo Elitão. São Paulo: Campinas, Editora da Unicamp, 2003. P.17-171. 
LEE, Peter. Progressão da compreensão dos alunos em História. In. BARCA, Isabel. (org) Perspectivas em educação histórica. Actas das primeiras jornadas internacionais de educação histórica, p. 20, 2001.

NÓVOA, Antonio. Nota de Apresentação. In: GOODSON, Ivor F. A Construção Social do Currículo. Tradução: Maria João Carvalho. Lisboa: EDUCA, 2002.

OLIVEIRA, Margarida; FREITAS, Itamar. Currículos de história e expectativas de aprendizagem para os anos finais do ensino fundamental no Brasil (2007- 2012). Revista História Hoje, São Paulo, v. 1, n. 1, p. 269-304, 2012.

RAMOS, Márcia Elisa Teté. O ensino de história na revista Nova Escola (1986-2002) : cultura midiática, currículo e ação docente. 2009. Tese (Doutorado em Educação)Universidade Federal do Paraná, Curitiba. Curitiba, 2009.

SILVEIRA, Fernanda Romanezi. Um estudo das Capas da Revista Nova Escola: 19862004. 2006. Dissertação (Mestrado em Educação)-Universidade Estadual de Campinas, Campinas.

SCHMIDT; Maria Auxiliadora; CAINELLI, Marlene. Ensinar história. 2 ed., São Paulo: Scipione, 2010. 